\title{
Design and Experimental Research of Agricultural Low Power Single- phase Frequency Conversion Control System Based on SPWM
}

\author{
Chuanlai Yuan, Lingshuang Kong*, Can Hu and Weilong Zhou
}

\author{
College of Electrical and Information Engineering, Hunan University of Technology, Zhuzhou, 412007, China
}

\begin{abstract}
In the countryside of China, the main power supply mode is $220 \mathrm{~V}$ single-phase power, which affects the widely application of three-phase agricultural appliances. What's more, it means a block to the development of modern agriculture. However, frequency converter technique research is focused on three-phase high power frequency conversion technology at present, and there are very few achievements on the agricultural low power single-phrase frequency conversion research. In this paper, considering the difficulty of widely application of agricultural low power three-phase AC motor because it is not easy to obtain the three-phase power supply, a three-phase AC frequency conversion system under the condition of agricultural $220 \mathrm{~V}$ single-phase AC power is designed, which can achieve the stepless regulation of the voltage amplitude and guarantee the widely use of the three-phase AC motor under the condition of agricultural $220 \mathrm{~V}$ singlephase AC power. The experimental results show that the system can output the controlled three-phase AC power when the input is $220 \mathrm{~V}$ single-phase AC power. And the rational design of the system hardware also provides the technical support for the application of agricultural low power frequency conversion.
\end{abstract}

Keywords: SPWM, Low power motor, Single-phase AC frequency conversion.

\section{INTRODUCTION}

With the extensive application of frequency conversion technology, scientific research workers have researched AC frequency conversion technique in depth and developed a large number of new methods of frequency conversion since the last century [1-5]. Liu Jian has improved and developed the high voltage frequency conversion speed governing system through the improvement of the traditional three-level circuit. Xiao Yunqi, Xu Daping and others have optimized SPWM algorithm model and presented a simplified model. Yi Longqiang, Dai Yuxing and others have proposed a SPWM pulse multiple technology, so the harmonic content of SPWM waveform has been reduced again.

However, the current research on inverter technology is mainly focused on medium and high power three-phase AC frequency conversion, ignoring the agricultural low power research of frequency conversion technology, and leads to the specific design of agricultural single-phase inverter system is less [6]. In the countryside of China, the main power supply mode is $220 \mathrm{~V}$ single-phase power supply which brings about pretty restriction to three-phase agricultural appliances. What's more, it means a block to the development of modern agriculture. At the same time, in the wake of the agricultural appliances are used extensively to agriculture and household appliances, we starve for a way of power transformation to change the status. This actual problem can be resolved by the frequency conversion technology which contains low power single-phase input and three-phase AC output. For this reason, this article designs a set of singlephase AC frequency conversion speed governing system based on SPWM algorithm. Single-phase AC 220V is used as the input source of the system. First of all, we should let it go through the uncontrollable single-phase bridge rectifier circuit. Secondly, we can secure a stable 270 V DC voltage after it is filtered by large capacitor. Finally, we cannot obtain the three-phase AC adjustable amplitude voltage which is adjustable to three-phase AC motor's work until after passing through the three-phase bridge inverter circuit.

\section{DESIGN SCHEME OF SYSTEM}

According to the basic principle of variable frequency control, the system uses a constant $\mathrm{V} / \mathrm{F}$ ratio control and keeps a linear relationship between the input voltage amplitude and frequency to realize the SPWM control by microcontroller.

\subsection{Structure and Function of System}

The system adopts the typical AC-DC-AC structure of power electronic variable voltage and variable frequency with the structure diagram shown in Fig. (1). After singlephase AC $220 \mathrm{~V}$ through the uncontrollable single-phase bridge rectifier circuit and large capacitor filter as input, it becomes stable DC $270 \mathrm{~V}$ voltage. Thus, we can get the output through the three-phase full wave inverter circuit. Meanwhile, the control circuit can calculate the size of the frequency modulation and amplitude modulation, makes a comparative analysis on the output current of inverter feedback, get the perfect control waveform by opening and shut- 


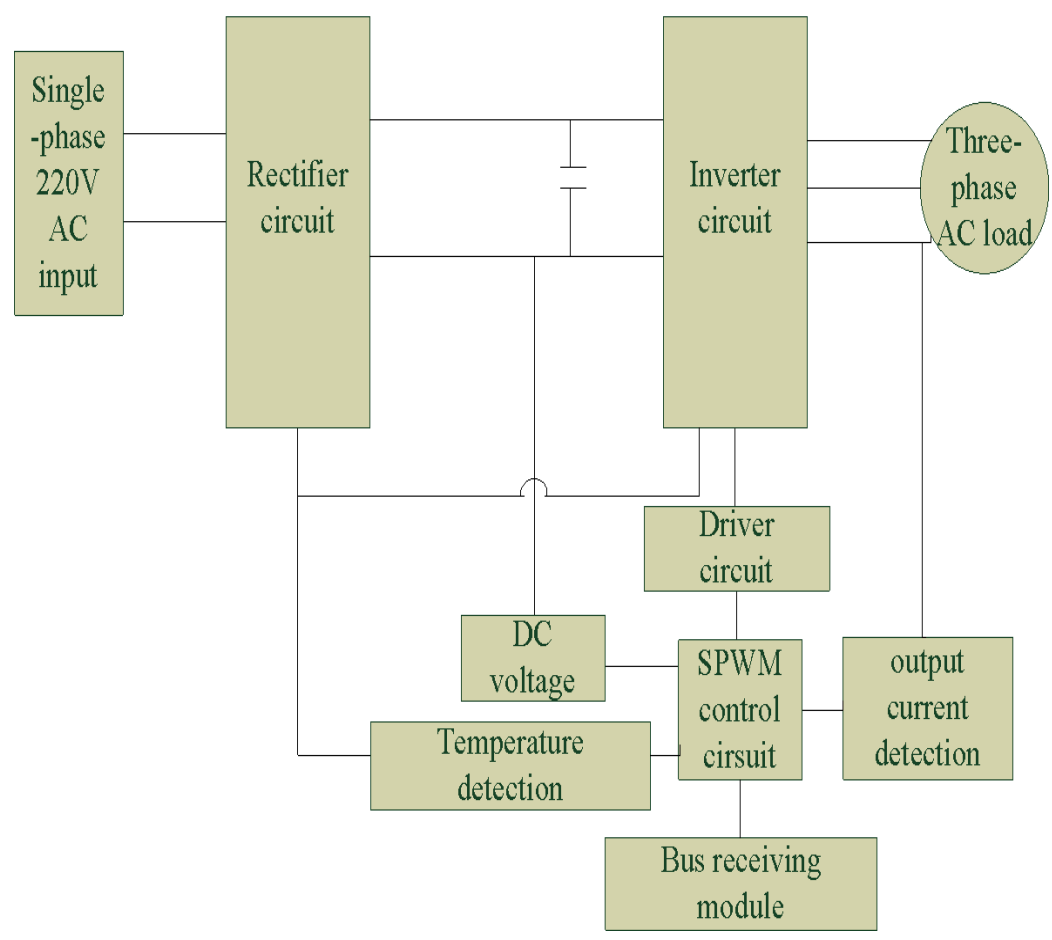

Fig. (1). Structure Diagram of System.

ting the drive switching device IGBT and finally output the three-phase AC adjustable frequency amplitude voltage. The main functions of the system include DC voltage detection, output current acquisition, temperature acquisition and protection, short-circuit protection and over-current protection. 16 bit microcontroller dsPIC30F6010A [7] have been chosen by the control circuit of the control system to achieve related functions, such as the regulation of individual parameter and system protection.

\subsection{Principle of SPWM Waveform Algorithm}

According to the Fourier analysis, the fundamental frequency range of the SPWM waveform output is described as follows:

$U_{I m}=U_{m}\left[\mathbf{1}-\frac{\boldsymbol{1}}{\mathbf{N}} \sum_{i=1}^{N} \cos (2 i-\mathbf{1}) \frac{\boldsymbol{\pi}}{\mathbf{N}}\right]$

Where $\mathrm{N}$ is the number of pulse width in half a waveform and where Um is the amplitude of the input voltage. When $\mathrm{N}>1, \mathrm{U} 1 \mathrm{~m}>\mathrm{Um}$ and output voltage fundamental wave is a sine wave required in the modulation. Moreover, we can also learn the SPWM method will reduce low order harmonics effectively, with the presence of high harmonics [8-11]. Indeed, the voltages added to three-phase winding of AC induction motor are shown respectively as follows:

$e u 1=E m s i n \omega t$

$e u 2=\operatorname{Emsin}\left(\omega t+180^{\circ}\right)$

Where $E_{m}$ is the amplitude of the voltage and where $\omega$ is the angular frequency of the input voltage defined as $\omega=2 \pi \mathrm{f}$. Besides $\mathrm{f}$ is the frequency of the voltage, in other words, it's the modulating frequency of the waveform generator. After the three-phase voltage with 120 degree phase difference among each phase is added to the winding of the induction motor, the system will produce the three-phase current, form a round rotating magnetic field and drive the rotation of the motor rotor. When the control uses the constant V/F ratio, there is a linear relationship between the input voltage and frequency. While the controlled motor usually has a simple linear relationship, we can use the calculation method to take the place of the V/F table. The specific calculation procedure of $\mathrm{V} / \mathrm{F}$ control is described in Fig. (2).

\section{SPWM CONTROL CIRCUIT OF SYSTEM}

As shown in Fig. (3), the SPWM control circuit is mainly composed of dsPIC30F6010A microcontroller, MC54HC 244, PNP, Q1, power transistor, capacitors and resistors etc. $\mathrm{R} 1$ is not only the collector resistance of Q1 but also pull-up resistance of MC54HC244. It enhances the noise immunity of chip input signal and the anti-interference ability by making the signal is on high potential. In addition, it can also limit the current. $\mathrm{C} 1$ connects $+5 \mathrm{~V}$ power source and ground as a supporting capacity, and plays a role of the battery. When the inverter works properly, the system can provide a high potential signal for fault pin FLTA of microcontroller by comparing the numerical value of current detection with the numerical value of SPWM calculation and allow the output of SPWM wave. At the same time, Q1 is on, enable terminal G of MC54HC244 is low and its leading-out terminal Y can output SPWM signal. On the other hand, when the 


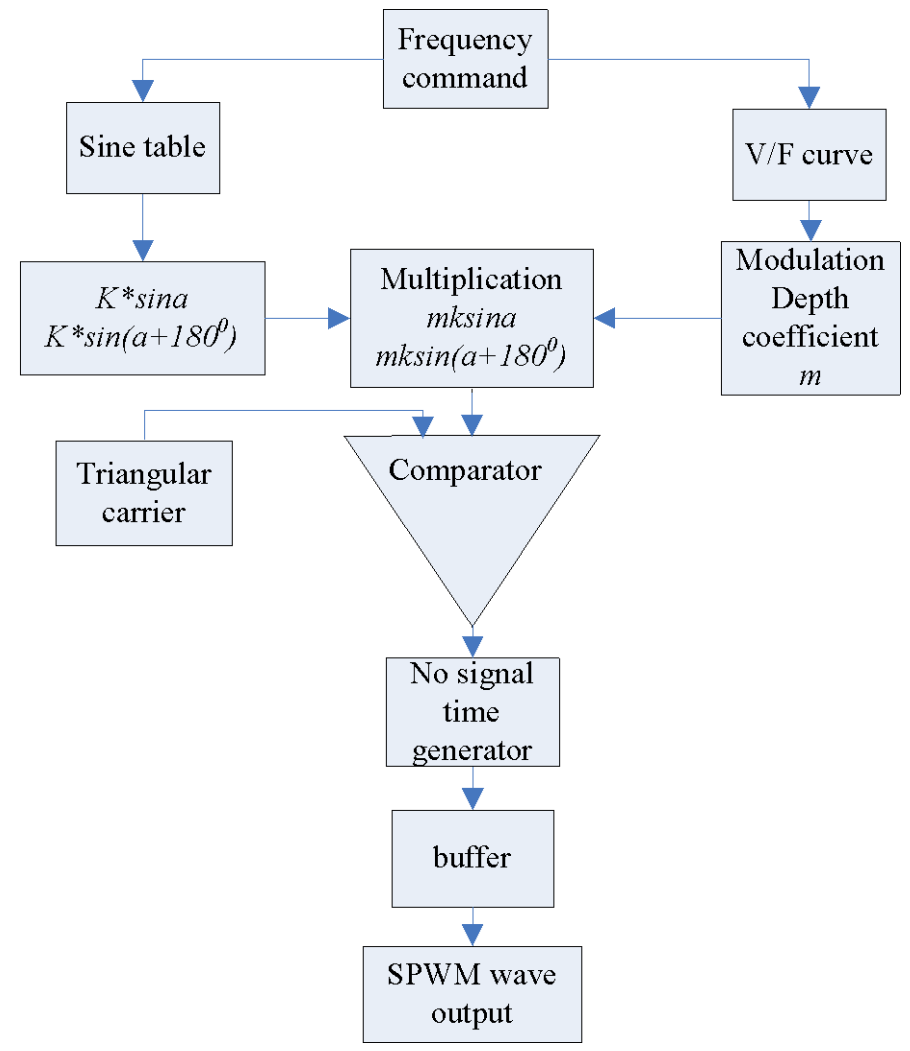

Fig. (2). Calculation procedure of V/F control.

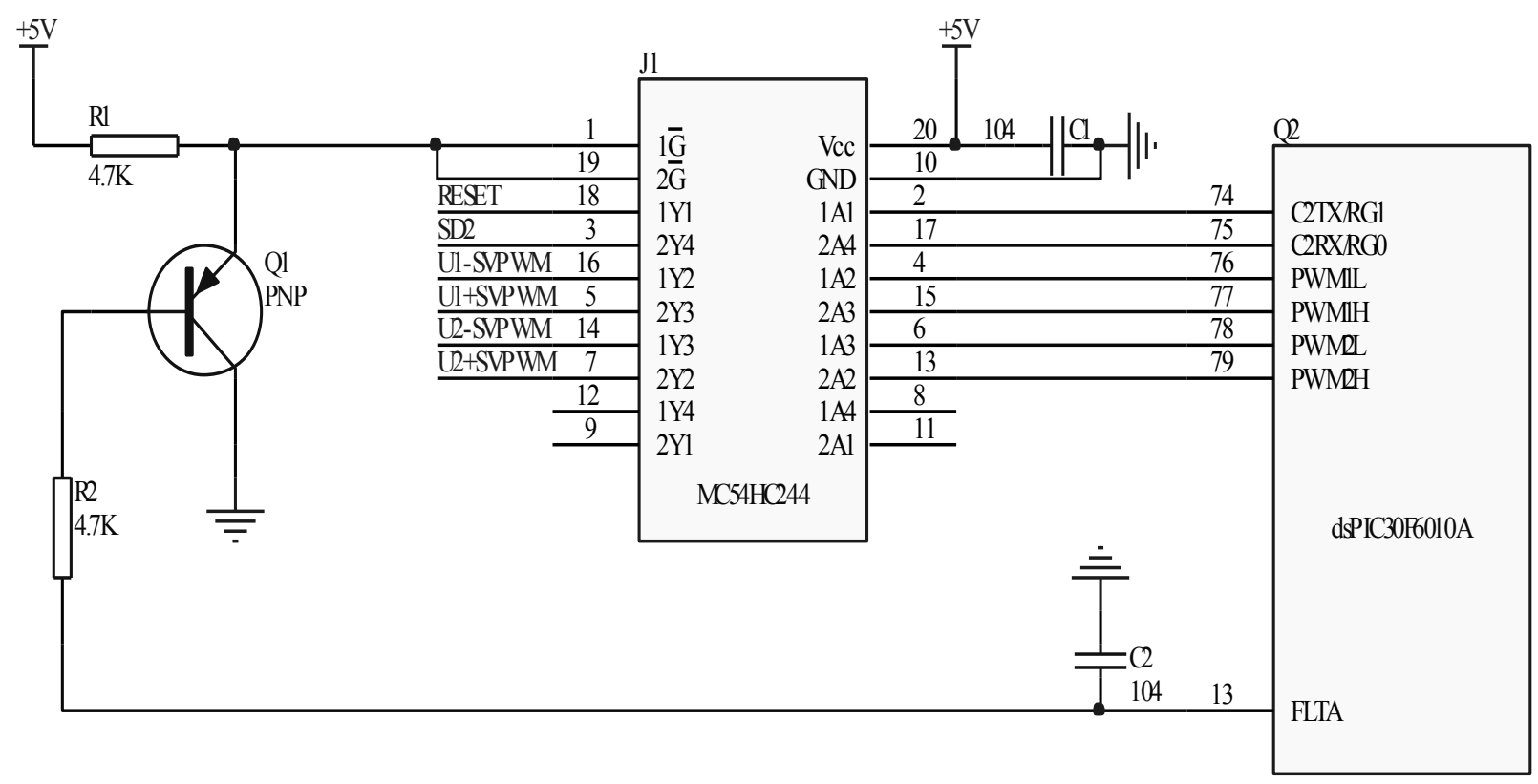

Fig. (3). Control circuit of SPWM.

inverter faults the short-circuit, Q1 is off, enable terminal G of MC54HC244 is low, leading-out terminal Y cannot output SPWM signal and the system realizes the function of hardware protection. Besides, fault pin of microcontroller connects a low potential, blocks the output of SPWM wave and realizes the function of software protection.

\section{SOFTWARE IMPLEMENTATION OF SPWM SYS-} TEM

The major task of the system is bringing SPWM wave for the driving circuit to drive IGBT inverter circuit, dealing with the feedback signal of the sampling circuit and achieving the control of voltage and current. The main program 


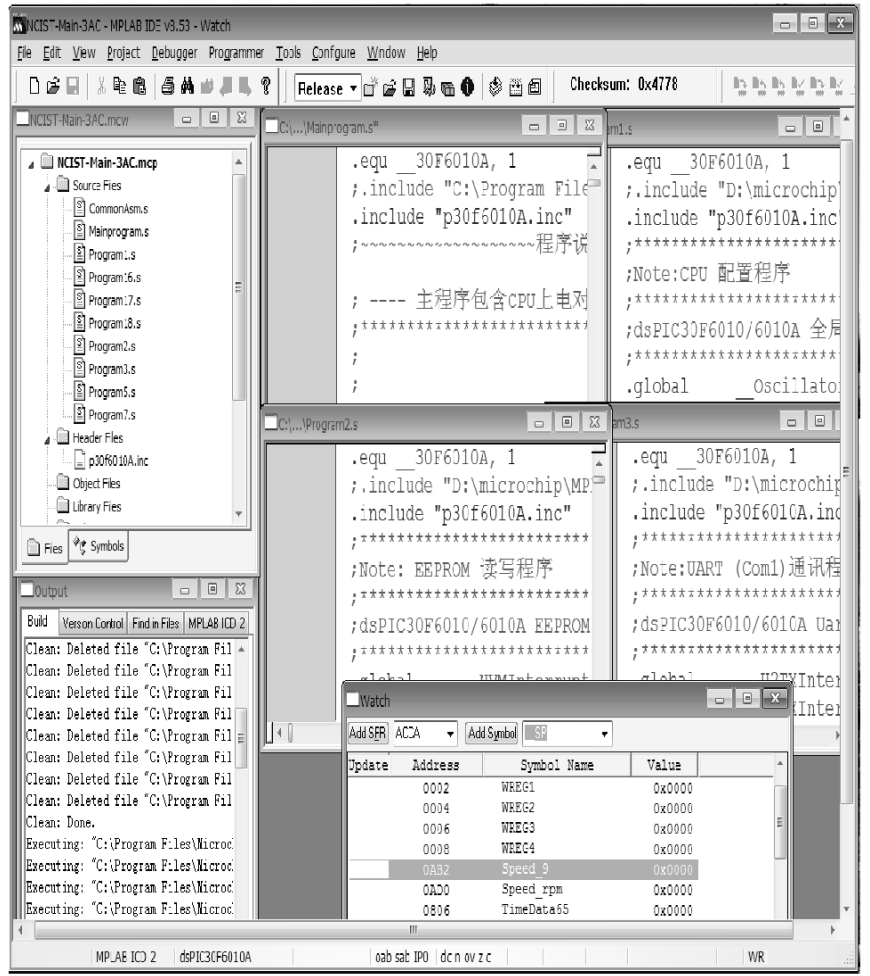

a. MPLAB IDE 8.53 interface
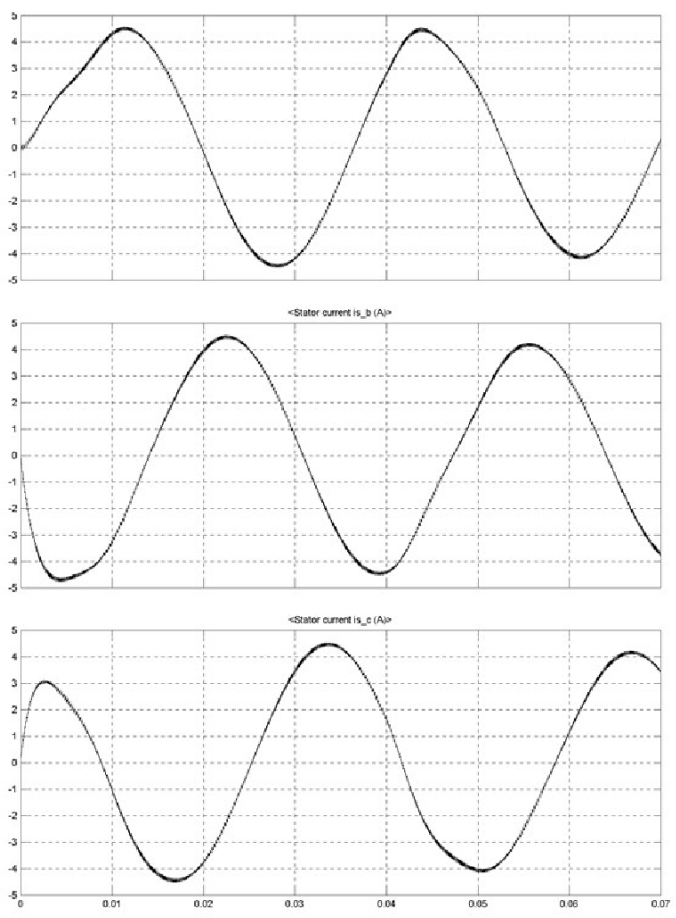

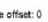

b. Current waveform of system output

Fig. (4). Debugging Software Of The System And Output Current In The Load Experiment.

design of SPWM wave consists of five parts: initialization, the identification of edge parameters, the calculation of frequency and amplitude, phase increment and the calculation of amplitude modulation coefficient [12]. Initialization also includes I / O ports, SPWM time-base register and the A / D conversion settings. For the SPWM control register, we can configure the following: making the SPWM timer works in the SPWM occurrence normal way, choosing cycle match as the way to remove the clock timer, setting the interrupt once per cycle and using the rising edge of the clock as the count edge.

\section{LOAD EXPERIMENT OF SINGLE-PHASE IN- VERTER SYSTEM}

(1) Before the experiment, the first thing we should do is to debug single-phase inverter system by using the online debugger MPLAB ICD2 in the MPLAB software integrated development environment IDE 8.53. MPLAB IDE software is a desktop environment used to develop and debug the toolkit of Microchip Microcomputer design and application. And many Microchip development system tools use MPLAB IDE as a common user interface, such as MPLAB editor, MPLAB ASM30 assembler, MPLAB SIM software simulator, MPLAB LIB3 library, MPLAB LINK30 linker, MPLAB ICE 4000 MICE, PRO MATE II programming unit and
Online modulator ICD2. As shown in Fig. (4), this is the interface of IDE 8.53. We can debug single-phase inverter system online and test the performance of the system by using the software of MPLAB. And the software of MPLAB can record the experimental parameters and realize the wire monitoring to the output curve of frequency converter under the load experimental conditions.

(2) When experiments are to be made, a Y series motor of $2.2 \mathrm{KW}$ three-phase $380 \mathrm{VAC}$ connects to the output terminal of single-phase inverter system so as to drive the blower load. Single-phase AC 220 V power supply connects to the input terminal of single-phase inverter system from the lower end of $16 \mathrm{~A}$ air-break switch in the laboratory.

(3) We should do the electricity experiment before setting up the experiment. Then we connect the converter to the computer through a RS232 interface. What we must do next is to run MPLAB software. The MPLAB software can monitor operating data online, and record the data in a way of controlling the speed of the motor by input frequency.

(4) According to the connection mode of the motor, we do the experiment in two groups. Each group measures operating parameters with the changes of frequency, and records the operating data separately when the connection mode is Y-connection or delta connection. 
Table 1. Operating Data of Single-Phase AC Inverter System with Fans Load.

\begin{tabular}{|c|c|c|c|c|}
\hline Motor Connection Mode & Control Frequency (HZ) & Output Current (A) & Motor Speed (r/min) & Wind $(\mathrm{m} / \mathbf{s})$ \\
\hline $\mathrm{Y}$ & 10 & 12.8 & 112 & 4.2 \\
\hline $\mathrm{Y}$ & 20 & 9.2 & 320 & 7.5 \\
\hline $\mathrm{Y}$ & 35 & 7.5 & 754 & 11.2 \\
\hline $\mathrm{Y}$ & 50 & 5.2 & 1248 & 18.9 \\
\hline$\triangle$ & 20 & 8.1 & 384 & 8.2 \\
\hline$\triangle$ & 35 & 6.2 & 801 & 13.4 \\
\hline$\triangle$ & 50 & 4.3 & 1265 & 20.4 \\
\hline
\end{tabular}

\section{EXPERIMENTAL RESULTS AND ANALYSIS}

(1) The experimental results are shown in Table 1. System tests expatiate that single-phase inverter system can effectively output three-phase power satisfied the requirement of control when the input power is AC $220 \mathrm{~V}$.

(2) Just as the change of the connection modes of motor, the experimental results changes when input frequency is the same. Indeed, compared with delta connection, motor current is larger and its loading capability is weaker when motor adopt the connection mode of Y-connection. If motor use the delta connection, motor current is more normal and its loading capability is stronger. And its loading capability is the same as rating value under the condition of $50 \mathrm{HZ}$.

(3) Because single-phase inverter system lacks the capability of improving voltage, it produces the output voltage of three-phase $220 \mathrm{~V}$ when the input voltage is AC $220 \mathrm{~V}$. We should change the connection mode to delta connection, so as to meet the requirements of inverter system in the load experiment.

(4) Single-phase inverter system has consistently reliable performance and can output a stable three-phase current waveform as shown in Fig. (4b). It is suitable for agricultural three-phase load required frequency speed under $5 \mathrm{KW}$.

\section{CONCLUSION}

We test the performance of agricultural low power single-phase frequency speed system by load experiment.

(1) The system structure is reasonable and its I/O process is stable. So system can realize the following functions: inputting low power single-phase AC, exporting three-phase $\mathrm{AC}$ and controlling the speed of the motor.

(2) Microcontroller output a stable and reliable SPWM waveform, and sinusoidal AC waveform of inverter output is suitable for low power three-phase AC motor under $5 \mathrm{KW}$.
(3) We should pay more attention to the influence on the connection modes of motor in practical application. If motor use the delta connection, its loading capability will stronger.

\section{CONFLICT OF INTEREST}

The authors confirm that this article content has no conflicts of interest.

\section{ACKNOWLEDGEMENTS}

The work is supported by the National Natural Science Foundation (No. 61203136), and the science and Hunan Provincial Natural Science Foundation of China (No. 2015JJ5025).

\section{REFERENCES}

[1] R. Sriram, and P. Muthu. Kumaran, "Digital implementation of sinusoidal pulse width modulation generator," International Journal of Technology Enhancements and Emerging Engineering Research, vol.2, pp.2347-4289, 2014.

[2] D. Ahirrao, B. Gaware, P. Kakade, P. Kharade, and S.Chawda, "Analysis of single phase matrix converter," Int. Journal of Engineering Research and Applications, vol.4, pp. 27-30, 2014.

[3] S.B.Patil, and M.S.Aspalli, "Operating three phase induction motor connected to single phase supply," International Journal of Emerging Technology and Advanced Engineering, vol.2, pp. 523-528, 2012

[4] M. Lakka, E. Koutroulis, and A. Dollas, "Development of an FPGA-Based SPWM Generator for High Switching Frequency DC/AC Inverters," IEEE Transactions on Power Electronics, vol. 29, pp.356-365, 2014.

[5] S. Undrajavarapu, S. Rao, and L.U. Kiran, "Pv fed boost spwm inverter driven single-phase induction motor," Int. Journal of Engineering Research and Applications, vol.2, pp. 2136-2141, 2012.

[6] L.Yi, Y.Da, and H.Quan, "Pulse-multiplied based digital SPWM technique," Journal Of Hunan University(Natural Sciences), vol.5, pp. 36-40, 2008

[7] Y. Xie, and O. Sen, "Single chip microcomputer control of power electronics technology," Beijing:Mechanical Industry Publishing House, pp.107-142, 2007.

[8] Y. Zhang, "SPWM frequency control technology," Beijing: Mechanical Industry Publishing House, pp.55-59, 2011. 
[9] T.L. Grant, and T.H. Barton, "Control strategies for PWM Drives," IEEE Trans, vol, 03, pp. 211-215, 2010.

[10] Y. Xiao, D. Xu, and Y. Lv, "Simplified model for ac-dc-ac converter system based on SPWM," Journal of System Simulation, pp.2185-2189, 2008.

[11] B.Kbose, "Power Electronic And AC Drivers," Xian: Jiaotong University Publishing House, pp.231-265, 2009.
[12] J. Liu, "A new three-level high voltage variable frequency speed control technology and equipment research and development," Wuhan: Huazhong University of science and Technology, pp.65-72, 2008.

Received: June 16, 2015

Revised: August 10, 2015

Accepted: September 19, 2015

(C) Yuan et al.; Licensee Bentham Open.

This is an open access article licensed under the terms of the Creative Commons Attribution Non-Commercial License (http://creativecommons.org/licenses/by$\mathrm{nc} / 3.0 /$ ) which permits unrestricted, non-commercial use, distribution and reproduction in any medium, provided the work is properly cited. 